\title{
Treatment of paroxysmal disorders in multiple sclerosis with carbamazepine (Tegretol)
}

\author{
MICHAEL L. E. ESPIR ${ }^{1}$ AND PAUL MILLAC \\ From the Department of Neurology, Leicester Royal Infirmary
}

SUMMARY During an eight year period, 32 patients with definite or suspected multiple sclerosis (MS) were seen with paroxysmal neurological disturbances, which included tonic seizures, paroxysmal dysarthria, paraesthesiae and pain in the limbs, as well as trigeminal neuralgia. In 21 of these patients the paroxysmal disorders were treated with carbamazepine, and in six the effect was compared with placebo. In the majority carbamazepine was effective in controlling the paroxysmal symptoms. Side-effects were troublesome in a few patients, but they could usually tolerate small doses, which still gave relief. Although the patho-physiological basis for these paroxysmal disorders remains unexplained, their response to carbamazepine suggests a common mechanism.

A variety of fleeting neurological symptoms are experienced by patients with multiple sclerosis (MS). Not uncommonly these are provoked by a hot bath, smoking, exertion, or flexion of the spine (McAlpine, Lumsden, and Acheson, 1965). Distinct from these are stereotyped disturbances recurring repeatedly in brief paroxysms. Such manifestations include tonic seizures, paroxysmal dysarthria, paraesthesiae and pain in the limbs, and trigeminal neuralgia. The similarity of trigeminal neuralgia to the other paroxysmal disturbances has been referred to previously (Espir, Watkins, and Smith, 1966; Espir and Walker, 1967). The paroxysms may each last from a few seconds to a minute or so, recurring several times an hour, apparently spontaneously but sometimes precipitated by various stresses. These bouts usually remit and may be forgotten if they occur early in the disease, or are overshadowed later by more permanent disability; for this reason their incidence has probably been underestimated. The value of carbamazepine in the treatment of trigeminal neuralgia, whether or not it is associated with MS, is now generally accepted, and evidence is accumulating that it also controls other types of paroxysmal disturbances in MS. We wish to report here our experience with carbamazepine in the treatment of such disturbances, including a comparison with placebo in six patients.

${ }^{1}$ Present address: Regional Department of Neurosurgery and Neurology, Derbyshire Royal Infirmary, Derby.

\section{PATIENTS AND METHOD}

Among approximately 600 patients with undoubted of suspected MS seen by one of us (M.L.E.E.) in Leices 2 ter between 1960 and 1968, 32 are known to have has paroxysmal disorders. This should not be regarded as ce the exact incidence, as earlier patients were not specifio in cally asked about such symptoms. During the last four. years, 21 of these patients have been treated with carba $\vec{\theta}$ mazepine and the results reviewed (see Table). In six 0 patients the effects of carbamazepine and placebo were compared. The regime for each preparation was $\frac{1}{2}$ tablet four times daily for one day and then a whole tablet four times daily for not less than three days. The drug and identical dummy tablets were thus provided successively on a random basis by the hospital pharmacist and only he knew the order in which they were administered until both had been taken for an equal period (a tablet of carbamazepine $=200 \mathrm{mg}$ ).

\section{RESULTS AND CASE REPORTS}

TONIC SEIZURES Five patients with MS and tonic seizures were seen. Three were treated with carbamazepine, all with benefit. One of these had very frequent complicated bilateral seizures and the effect of carbamazepine was dramatic. The other two are reported below; in case 1 the effects of placebo and carbamazepine were compared, and in case 2 treatment with carbamazepine was given for two separate bouts of tonic seizures on alternate sides.

CASE 1 A hosiery worker, aged 46, noticed numbness of his right arm and leg in December 1967 after a head cold. His right leg felt weak and made him limp. Three 
TABLE

DATA OF PAROXYSMAL DISORDERS AND TREATMENT

\begin{tabular}{|c|c|c|c|c|c|c|c|}
\hline $\begin{array}{c}\text { Type of } \\
\text { paroxysmal } \\
\text { disorder }\end{array}$ & $\begin{array}{l}\text { Patients } \\
\text { (no.) }\end{array}$ & $\begin{array}{r}\text { Sex } \\
F / M\end{array}$ & $\begin{array}{c}\text { Mean age } \\
\text { at onset } \\
\text { of paroxysms } \\
(y r)\end{array}$ & $\begin{array}{l}\text { Mean } \\
\text { duration of } \\
\text { bouts of } \\
\text { paroxysms } \\
\text { (mth) }\end{array}$ & $\begin{array}{c}\text { Patients } \\
\text { treated with } \\
\text { carbamazepine } \\
(\text { no. })\end{array}$ & $\begin{array}{c}\text { Mean dose } \\
\text { of } \\
\text { carbamazepine } \\
\text { (mg/day) }\end{array}$ & $\begin{array}{c}\text { Patients with } \\
\text { troublesome } \\
\text { side-effects } \\
\text { (no.) }\end{array}$ \\
\hline $\begin{array}{l}\text { Tonic seizures } \\
\text { Dysarthria } \\
\text { Paraesthesiae } \\
\text { Pain in limbs } \\
\text { Trigeminal neuralgia }\end{array}$ & $\begin{array}{l}5 \\
8 \\
3 \\
7 \\
9\end{array}$ & $\begin{array}{l}3 / 2 \\
5 / 3 \\
1 / 2 \\
5 / 2 \\
6 / 3\end{array}$ & $\begin{array}{l}31 \\
39 \\
40 \\
40 \\
47\end{array}$ & $\begin{array}{l}1 \frac{1}{2} \\
3 \\
18 \\
20 \\
40\end{array}$ & $\begin{array}{l}3 \\
4 \\
3 \\
6 \\
5\end{array}$ & $\begin{array}{l}700 \\
300 \\
400 \\
500 \\
760\end{array}$ & $\begin{array}{l}1 \\
1 \\
2 \\
3 \\
1\end{array}$ \\
\hline Total & 32 & & & & 21 & & \\
\hline
\end{tabular}

weeks later he developed 'cramps' affecting his right arm and leg which became rigid and painful. The right side of his face was also involved and speech slightly slurred. These attacks lasted only a few seconds and recurred up to a dozen times per day. Sometimes they were provoked by rising from a sitting position or lying on his right side. Quinine given by his general practitioner had no effect. In hospital his attacks were witnessed and could be provoked readily by hyperventilation. The right arm and leg flexed slightly, and the muscles felt firm as the fingers and toes became tightly clenched. Examination between paroxysms revealed ataxic nystagmus in both directions of lateral gaze, incoordination of the right limbs, and bilaterally increased tendon reflexes with absent abdominal responses. There was slight dysarthria and ataxia of gait. The cerebrospinal fluid (CSF) and routine investigations, including serum calcium, were normal. An electroencephalogram (EEG) was within normal limits, remaining unaltered during attacks and hyperventilation. Placebo was given first without effect. He was then given carbamazepine and after taking two tablets his attacks ceased. He discontinued treatment after four days without recurrence. Concurrently with a course of ACTH injections over the next month, all symptoms subsided and there has been no relapse during two years of follow up.

CASE 2 A woman aged 23, with characteristic manifestations of MS had her first bout of tonic seizures in September 1966. Frequent spasms affected her right side, but responded well to carbamazepine $600 \mathrm{mg}$ daily. After a week the drug was withdrawn without recurrence. In October 1968 she had her second cluster of tonic seizures, on this occasion affecting her left side. She was then unable to tolerate more than $200 \mathrm{mg}$ of carbamazepine daily, and responded less convincingly, although the seizures gradually diminished over the next few weeks.

PAROXYSMAL DYSARTHRIA Eight patients with paroxysmal dysarthria have been seen. Six were reported previously by Espir et al. (1966), and two of these (cases nos. 5 and 6) were treated successfully with carbamazepine; subsequently both have had further relapses typical of MS. Another patient with MS and paroxysmal dysarthria which responded drama- tically to carbamazepine was the subject of an additional communication (Espir and Walker, 1967).

We have also seen a further patient who has had two bouts of paroxysmal dysarthria, and with the second of these it was possible to compare the effects of carbamazepine and placebo.

CASE 3 A woman, aged 27, had her first symptons of MS in September 1962. These consisted of frequent transient attacks of vertigo and tingling in the left arm, which stopped after about two months. In December 1962 she complained of transient episodes of numbness of the right side of the face and right arm with slurred speech, lasting for less than a minute at a time, but recurring approximately every half hour. The significance of these attacks was not appreciated at the time. She was treated with a compound tablet containing ergotamine tartrate and phenobarbitone (Bellergal) and then with prochlorperazine without benefit, but the attacks ceased after about three months. In November 1967 brief paroxysms of dysarthria, with numbness of her left upper lip and ataxia, recurred up to 10 times each day. During a week on placebo, attacks continued with the same frequency. After two doses of carbamazepine the attacks stopped, but treatment was discontinued four days later because of side-effects. The paroxysmal dysarthria recurred and was then controlled by $50 \mathrm{mg}$ carbamazepine four times daily, which she continued for three months. Since this time she has remained free from paroxysmal disturbances, despite increasing disability from spastic paraparesis with sensory impairment in both legs.

PAROXYSMAL PARAESTHESIAE Three patients with probable MS have been seen with repetitive stereotyped sensory disturbances affecting the limbs. They were all improved by small doses of carbamazepine though in two side-effects were prominent. Placebo and carbamazepine were compared in one of these patients.

CASE 4 A factory worker, aged 51, had a two year history of difficulty in walking due to stiffness and dragging of his left leg. He also complained of a burning sensation in this limb, coming in bouts lasting three to four seconds, recurring as often as every 20 minutes but with varying 
frequency over the two year period. During the last year his right hand had become weak with numbness of the third, fourth, and fifth fingers and he had paraesthesiae in both legs. Examination revealed a spastic tetraparesis with wasting and weakness of small muscles of the left hand without sensory loss. Investigations including plain radiographs of the spine, myelography, and CSF examination were negative. Placebo administered during a four day period when he was having frequent paroxysms of the burning sensation in the left leg afforded no relief. After the first day of treatment with carbamazepine, the paroxysms became infrequent and they ceased within four days. Treatment was then discontinued because of lightheadedness and ataxia, whereupon the paroxysms returned. They were subsequently controlled satisfactorily by $150 \mathrm{mg}$ carbamazepine daily which he has taken for 18 months.

The other two patients with paroxysmal paraesthesiae received carbamazepine only.

CASE 5 An electrical engineer, aged 37, with a probable diagnosis of MS, complained of bouts of paraesthesiae in both legs, sometimes aggravated by walking. These were relieved by $200 \mathrm{mg}$ carbamazepine daily. After three months he discontinued treatment and has had no recurrence during $2 \frac{1}{2}$ years of follow up.

CASE 6 A woman aged 54, with definite MS, experienced frequent tingling in her left leg which appeared to respond to $300 \mathrm{mg}$ carbamazepine daily, but assessment was complicated by her neurotic personality and co-existent depression.

PAROXYSMAL PAIN Seven patients had repeated short lived attacks of severe pain affecting one limb. Six had definite and one possible MS. In three of these the pain was associated with a transient sensory or motor disturbance in the same limb, but pain was the predominant feature.

Five of the patients in this group were male: one was not treated, and one had paroxysmal attacks of pain and weakness in his right leg, relieved by 600 mg carbamazepine daily. In the other three, carbamazepine and placebo were compared; in each carbamazepine was effective and placebo was not, as illustrated by the following case.

CASE 7 A man aged 43, had a five year history of MS with extensive neurological signs. In February 1968 he presented with frequent attacks of severe shooting pain in the neck and left arm, each lasting several minutes, often disturbing his sleep. The pain was not typical of nerve root involvement due to cervical spondylosis and was not relieved by a collar or various analgesics. There was no evidence of syphilis, or of any cardiac disease. Placebo had little effect but carbamazepine greatly reduced the frequency and severity of the attacks, though they still recurred approximately twice per week. He was last seen 18 months later, still taking $600 \mathrm{mg}$ carbamazepine daily to control the pain.
The other two patients in this group were women with advanced MS. They gained only partial relief from carbamazepine and could not tolerate more than $\mathbf{4 0 0} \mathrm{mg}$ daily.

TRIGEMINAL NEURALGIA This well-recognized complication was seen in nine patients with MS and these are included for comparison with the other groups of paroxysmal disorders. The mean age of this group was higher (see Table). One patient was not treated. Four were initially treated with phenytoin, two with relief. One of these however relapsed and, after a temporary response to carbamazepine, subsequently required an alcohol block. The remaining four patients were successfully treated with carbamazepine; one relapsed later and had an alcohol injection.

\section{DISCUSSION}

Despite the increasing recognition of these paroxysmal disturbances in MS during recent years, their cause remains obscure. They are frequently an early feature and were thought to be the initial manifestation of MS in six of the 32 patients in this series Hyperventilation sometimes provokes attacks, event within seconds, and we have the impression tha? anxiety is prominent in these patients. In patients with advanced physical disability and concomitan emotional disturbances, there may be scepticismb on the part of the physician regarding the organie? of nature of these paroxysmal disorders and the values. $\overrightarrow{0}$ of therapy. The double-blind comparison of carba? mazepine and placebo in the subjects reported here left no uncertainty about the efficacy of the drug. While carbamazepine's side-effects may interfere with 'double blind' administration, the therapeutic response usually preceded their onset by several days, and in several instances relatively small doses of carbamazepine (100 to $200 \mathrm{mg}$ daily) were useful in suppressing attacks. Benefit was often evident within 48 hours and, once treated, the paroxysms not infrequently remitted. Patients with trigeminal neuralgia, as might be expected, tolerated larger doses of carbamazepine than those with paroxysms of tingling in their limbs.

Although other anti-convulsant drugs have been effective in some cases (Matthews, 1958; Espir and Walker, 1967) these paroxysmal disorders are not regarded as epileptic and EEGs taken during bouts have not been disturbed. Furthermore, the superiority of carbamazepine over phenytoin parallels that witnessed in the management of trigeminal neuralgia (Lewis, 1969). Kuroiwa and Shibasaki (1967) using carbamazepine and placebo in a double blind trial, also found that the drug was effective in controlling 
various types of tonic seizures in four patients with MS. Harrison and McGill (1969) reported a patient with paroxysmal dysarthria which responded to carbamazepine but not to phenobarbitone, primidone, or placebo. They considered that the transient attacks might have arisen from a build up of post-synaptic facilitation from a discharge around the brain-stem plaque, and that carbamazepine might suppress this phenomenon.

Ekbom, Westerberg, and Osterman (1968) reported two patients with focal sensory-motor seizures of spinal origin resembling the cases we have reported, in that attacks were of brief duration. recurred frequently, and in one of their cases ceased within 24 hours when carbamazepine was administered. They assumed that these seizures were due to an irritative lesion with a transversely spreading activation of axons at the affected level in the spinal cord, thus explaining the crossed distribution of the tonic spasm and the sensory disturbances that they described. In a similar case reported by Castaigne Cambier, and Brunet (1968) carbamazepine also arrested the seizures within 24 hours and these authorsagreed with the explanation given by Professor Ekbom and his colleagues.

Our experience confirms the value of carbamazepine in suppressing paroxysmal symptoms in MS and the dramatic response made by some patients with differing paroxysms suggests a common mechanism. Whatever the underlying cause, it seems likely that paroxysms result from a degree of demyelination insufficient to give persistent deficit, but rendering axons hypersensitive to minor stresses.
We are grateful to Dr. Douglas McAlpine for valuable advice in the preparation of this paper; to Dr. Alan Galbraith, of Geigy (U.K.) Ltd., for supplying the dummy carbamazepine tablets; and to Mr. E. J. Fitchett, chief pharmacist at the Leicester Royal Infirmary, for dispensing the tablets. M.L.E.E. also acknowledges a research grant from the Multiple Sclerosis Society, and thanks Dr. M. E. Walker and Dr. Sylvia M. Watkins for their help with the study of patients with multiple sclerosis in Leicester.

\section{REFERENCES}

Castaigne, P., Cambier, J., and Brunet, P. (1968). Spinal sensory-motor seizures. Lancet, 1, 357.

Ekbom, K. A., Westerberg, C-E., and Osterman, P. O. (1968). Focal sensory-motor seizures of spinal origin. Lancet, 1, 67.

Espir, M. L. E., Watkins, S. M., and Smith, H. V. (1966). Paroxysmal dysarthria and other transient neurological disturbances in disseminated sclerosis. $J$. Neurol. Neurosurg. Psychiat., 29, 323-330.

Espir, M. L. E., and Walker, M. E. (1967). Carbamazepine in multiple sclerosis. Lancet, $1,280$.

Harrison, M., and McGill, J. I. (1969). Transient neurological disturbances in disseminated sclerosis: a case report. J. Neurol. Neurosurg. Psychiat., 32, 230-232.

Kuroiwa, Y., and Shibasaki, H. (1967). Carbamazepine for tonic seizures in multiple sclerosis. Lancet, 1, 116.

Lewis, I. (1969). Experiences with carbamazepine (Tegretol) in the treatment of facial pain (a report of 49 cases). Sth. med. J. (Bgham, Ala.), 62, 400-404.

McAlpine, D., Lumsden, C. E., and Acheson, E. D. (1965). Multiple Sclerosis: A Reappraisal. Livingstone: Edinburgh.

Matthews, W. B. (1958). Tonic seizures in disseminated sclerosis. Brain, 81, 193-206. 